\title{
APPLICATION OF DEEP LEARNING IN APPAREL DESIGN
}

\author{
Lesya Sviruk, Snizhana Kurochka, Oksana Zakharkevich \& Svetlana Kuleshova \\ Khmelnitskyi National University, Ukraine \\ Institytska str., 11, Khmelnitskyi, 29016, Ukraine \\ phone/ mobile: 38067-749-16-47 \\ e-mail: zbir_vukladach@ukr.net, kuleshova_lana@ukr.net
}

\begin{abstract}
Deep learning has many applications in contemporary world, which include the tasks of predicting the fashion as well as analysing the images of outfits and forming the textual description of the sketch. The paper is devoted to the examination of fashion search engines that probably could be utilised in apparel industry. Based on the results of performed online survey, it was determined that it is advisable to use as labels for the images specific features of the particular garment type rather than its name. Analysis of images of outerwear, which were obtained with the help of reverse image search, was conducted and images of women's duffle coats were selected. The selected material was sampled for the categorical principal components analysis and general assessment of differences of the garments images. It was determined that less than $30 \%$ of original population of images were sampled with required level of accuracy. All found images of the duffle coats cause the similar consumers' impressions. It was determined that deep learning can be used only for the purposes of similarity search for the online shops, which are oriented to the consumers' impressions rather than to retrieving the features of fashionable outfits.
\end{abstract}

Keywords: deep learning, garment type, training examples, clothing design.

\section{INTRODUCTION}

Although clothing design is one of the most creative realms in the contemporary world, it is a high developed technological industry as well. However, the great part of designers work is not performed with the help of computers. Whether it is because of considerable creative part of design process or equivocal information about clothing, the fact remains to be.

Internet shopping has grown incredibly in the last years, and fashion created an interesting application field for image understanding and retrieval, since hundreds of thousands images of clothes constitute a challenging dataset to be used for automatic or semi-automatic colour analysis, texture analysis, similarity retrieval and so on [5]. Such tasks are performed with methods of machine learning, part of which is deep learning. Deep learning trains a computer to perform human-like tasks, such as recognizing speech, identifying images or making predictions [12]. Instead of organizing data to run through predefined equations, deep learning sets up basic parameters about the data and trains the computer to learn on its own by recognizing patterns using many layers of processing.

Fashion is an entirely new direction for machine learning, but it is far from to be exception from the list of possible applications. The opportunities for deep learning in the fashion domain are very versatile. Researches all over the globe works with algorithms of machine learning, which are universal and therefore, it is possible to use them for the purposes of apparel design and fashion industry. For example, the results, which were described in [2], allow user to translate the image into the text that might as well be interpreted as a description of the garment based on its sketch. 
Fast and accurate fashion item detection model, based on deep neural networks, was proposed in [10]. Obtained by authors results make it possible to use their model for the task of fashion item detection and recognition, followed by visual similarity search.

To design clothes, one should know and understand the mechanisms of fashion: causes and spreading of the trends, principles of cyclic repetition and evolution patterns. Operating all the above, designers develop the fashion of tomorrow. The authors of [3] suggest that now the task of designing or predicting trends can be simplified, thanks to a new class of neural networks. These networks can automatically allocate shapes, elements and types of clothing and further combine them.

The dashboard developed by [9] allows seeing "how frequently a particular type of garment appears per day, what kind of apparel is popular within a certain age range, how people match their garments, etc." Authors [9] developed the graph showing the predictions of how popular certain types of garments would be over the next season that could be up to five months. This kind of analysis aims to help fashion retailers plan sales and avoid any surplus. Authors of [6] suggest that in the domain of visual search, with a focus on image similarity for online shops, understanding images of clothing means more than just classifying them into coarse categories. In order to get a meaningful description of the whole image, one needs to decompose the image into its parts. In addition, to train the machine to recognize the clothes, it is required to use a large dataset because of the great number of apparel categories [9]. Furthermore, in contrast to other domains, fashion images are usually annotated with one or more categories (label) since these pictures are often used directly in some kind of online shop or catalogue website or fashion portal.

However, fashion and apparel design are not exactly the same. Apparel design focuses on the garment manufacturing while fashion is concentrating on the clothing distribution. Hence, the application of deep learning in apparel design means to be of help for a patternmaker while deep learning in fashion is a help for a consumer or a fashion retailer. Thus, available fashion search engines are to be examined in order to determine the extent of their possible applications in domain of apparel design rather than fashion.

\section{METHODS}

In order to investigate the possible applications of deep learning in domain of apparel design it was determined to use the methods of online surveys as well as methods of statistical analysis and data mining. Statistical data of Google Trends [4] was used for the research of interest in deep learning. A set of images, which display a particular garment type, was obtained with Google reverse image search.

Consumer impressions from clothes, which were found by similarity search with tools of Google Images, were assessed with the help of method of semantic differential, which is described in [7]. Categorical principal components analysis was used to graphically display the relationship between the garment features that result in significant differences in appearances or impressions of the garments, which were found by similarity searching. The chosen method optimizes distances between objects and it is very useful for the primary interest is difference or similarity between the objects.

\section{EXPERIMENTAL}

According to information of the service Google Trends [4], the interest in deep learning is constantly increasing during the last decade all over the globe (figure 1, figure 2). 


\section{IRTTE}

Ipplied Reserer rhes in Technics, Technologies and Bduration Journal of the Faculty of Technics and Technologies, Trakia University https://sites.google.com/a/trakia-uni.bg/artte/

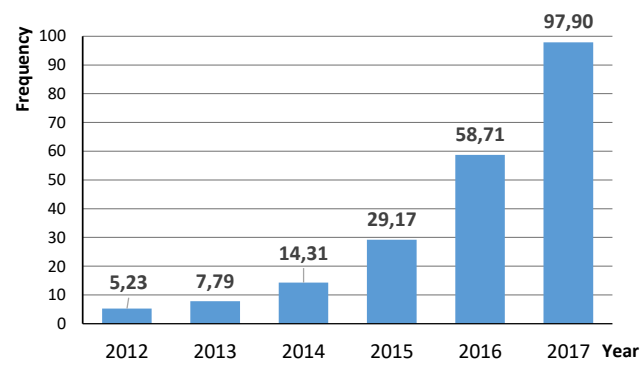

Figure 1. Interest in "Deep learning" by year

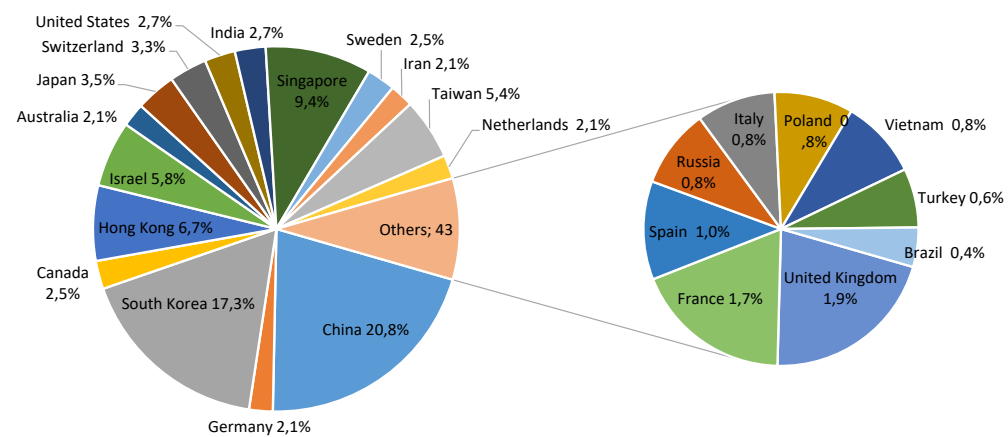

Figure 2. Interest in "Deep learning" by country

Although the interest in clothing search (or something like that) seems to be dramatically small, it can be considered as an application of the image search, the interest in which is considerably higher than the growing interest in deep learning (figure 3 ). Therefore, it is advisable to focus on the image search and recognition as well as its applications in the domain of clothing industry.
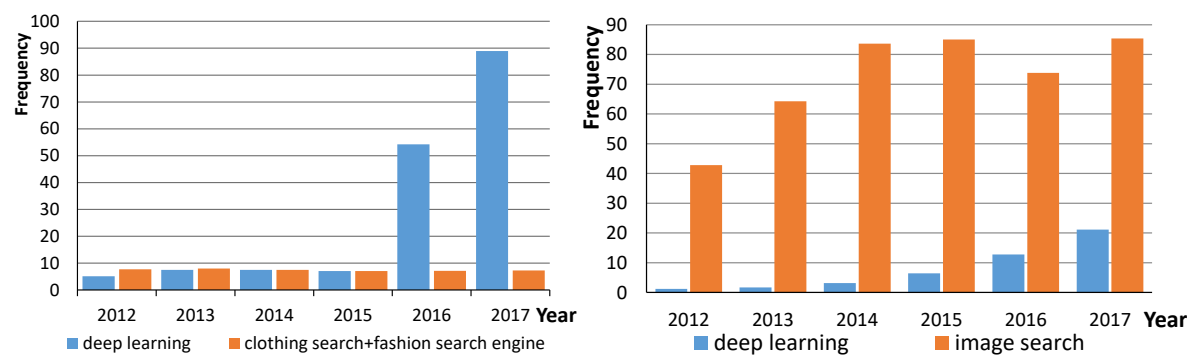

Figure 3. Comparison of interest in keywords regarding clothing and deep learning by year

Modern PDS-systems relay the functions of clothing designer to a user of computer. Presence of two design subsystems in such software, the first one of which aims at creating the sketch and the other one at drafting the garment construction, allows designing the garment in complete accordance with the original idea.

In the era of global digital technologies, most of the sketch creating subsystems most likely can be used for searching through the catalogues of apparel garments in the Web as well as for the review of online fashion shows in order to forecast the fashion tendencies and retrieving of the most frequently used elements of the fashionable outfits. Google Images is a search service owned by Google. It allows users to search the Web for image content and

IRTIIE Vol. 5, No. 3, 2017 ISSN 1314-8788 (print), ISSN 1314-8796 (online), doi: 10.15547/artte.2017.03.006 


\section{ART'TE $Y$}

Ipplied Resseirlores in Technics, Technologies and Educration

Journal of the Faculty of Technics and Technologies, Trakia University https://sites.google.com/a/trakia-uni.bg/artte/

most likely can be used for the garment search as well. Comparison of the specified fashion search engines, which were found as a result of the literature review, and search systems, which can be considered as such, is displayed in the table 1.

Table 1. Comparison of the actual fashion search engines

\begin{tabular}{|l|c|c|c|c|c|}
\hline Source & Purpose & Source of images & Implementation & Advantages & Disadvantages \\
\hline$[1]$ & $\begin{array}{c}\text { Recognition of } \\
\text { the coat's form }\end{array}$ & No information & - & $\begin{array}{c}\text { Oriented on } \\
\text { design }\end{array}$ & One category \\
\hline$[6]$ & $\begin{array}{l}\text { Image similarity } \\
\text { for online shops }\end{array}$ & $\begin{array}{c}\text { Catalogues of the } \\
\text { online shops }\end{array}$ & $\begin{array}{c}\text { Bonprix } \\
\text { Fashionhype }\end{array}$ & $\begin{array}{c}\text { Available demo } \\
\text { for the fashion } \\
\text { retailers }\end{array}$ & $\begin{array}{c}\text { White background; } \\
\text { unavailable for } \\
\text { consumers of the } \\
\text { online shops }\end{array}$ \\
\hline$[3],[9]$ & $\begin{array}{c}\text { Visual recognition } \\
\text { of visitors' } \\
\text { clothing in-store }\end{array}$ & Social media & - & $\begin{array}{c}\text { Uses any visual } \\
\text { content, trend } \\
\text { prediction }\end{array}$ & $\begin{array}{c}\text { Unavailable for } \\
\text { common user }\end{array}$ \\
\hline$[10]$ & Image similarity & $\begin{array}{c}\text { Catalogues of the } \\
\text { online shops, etc. }\end{array}$ & $\begin{array}{c}\text { Google images } \\
\text { search }\end{array}$ & $\begin{array}{c}\text { Available to any } \\
\text { user }\end{array}$ & $\begin{array}{c}\text { Obligatory white } \\
\text { background }\end{array}$ \\
\hline
\end{tabular}

According to [12], the question of differences between the specific garments types might cause the misunderstandings in design process due to the ambiguous definitions that lead designers to the completely different appearance of the garment.

Deep learning is a popular means of new era of technology that provides ability to exclude human factor and differences in experts' opinions from specific steps of design process. The supervised learning is the task of inferring a function from labelled training data that consist of a set of training examples. Deep learning in apparel design means that the training examples are labelled pictures of garment types. Therefore, in order to make a qualified fashion review or perform an online searching of specific garments with keywords, it is necessary to determine the description of each garment type. Differences in definitions of garments types especially in different languages cause problems with online search, preparing technical documentation, development and implementation of expert systems and other elements of artificial intelligence in apparel design.

Online survey that was performed through social networks in order to determine the name of the specific garment type, which is a duffle coat, shows that experts, whose area of expertise is clothing design, are not able to perform the task unanimously or even within statistical error (figure 4). The expert group consisted of 67 experts.
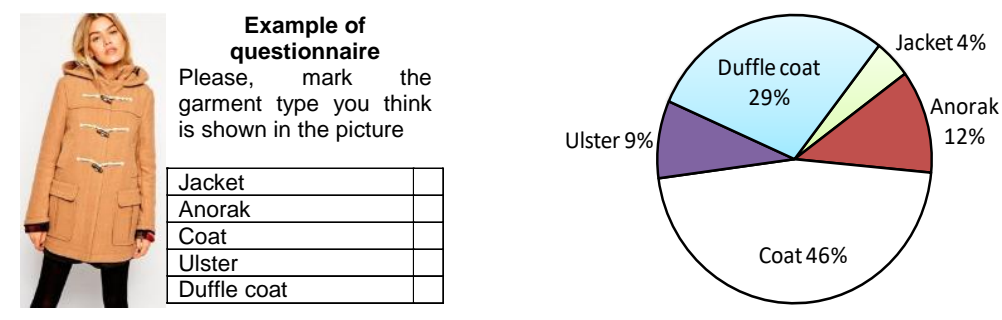

Figure 4. Results of survey in the social media

As it can be seen in the figure, only $29 \%$ of examined group were able to recognise a duffle coat in the image. Hence, it is advisable to use as labels specific features of the particular garment type rather than its name because the features are standard and can be determined specifically. In order to reveal the prospects of utilising the similarity search in the domain of apparel design actual image search was performed by tools of Google Images (figure 5). The original image is

IRTIIE Vol. 5, No. 3, 2017 ISSN 1314-8788 (print), ISSN 1314-8796 (online), doi: 10.15547/artte.2017.03.006 


\section{ARTTE $Y$}

Ipplied Resseirlores in Technics, Technologies and Educration

Journal of the Faculty of Technics and Technologies, Trakia University https://sites.google.com/a/trakia-uni.bg/artte/

the same one that was used for the online survey (see figure 5). As it displayed in the figure 6, only half of the found images might be of any aid for the designing purposes for the other half contains the images of different types of women's coats that are not the duffle coats.

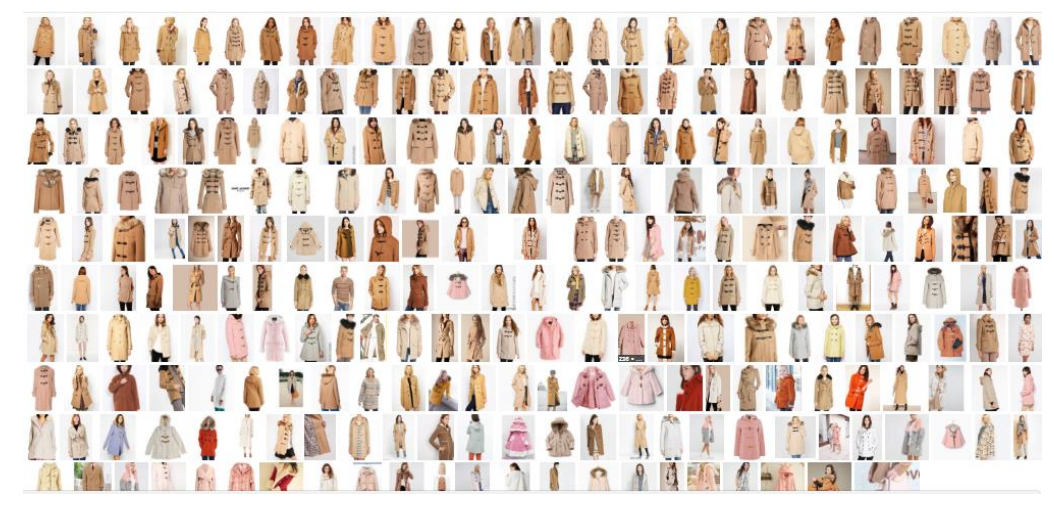

Figure 5. Results of the search by image algorithm of Google images

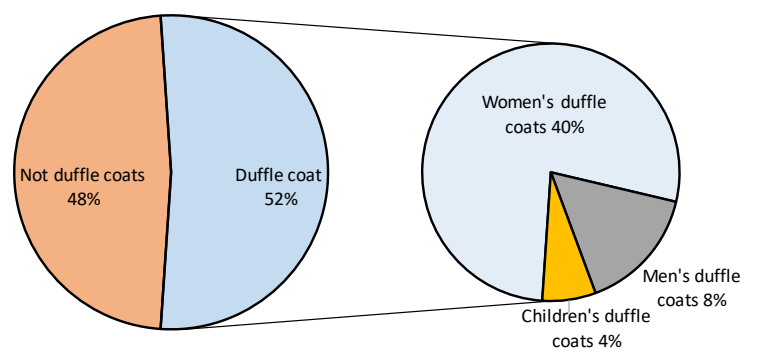

Figure 6. Quantity analysis of the images

Therefore, for the next step of current research the number of examined items decreased to the number of actual women's duffle coats. In order to use categorical principal components analysis, which would be performed with tools of the package PASW Statistics [6], every single garment was described with a code, which consisted of Arabian numerical codes of certain features of the garment (table 2). The list of the considered features is as follows: silhouette (S), length (L), form $(F)$, toggle-fastenings (TF), fastenings (Fs), yoke (Y), pockets $(\mathrm{P})$, hood $(\mathrm{H})$, trimming $(\mathrm{T})$, collar $(\mathrm{C})$, seams $(\mathrm{Ss})$, Cut (Cut). The garment that was the origin of the search has a code like follows: 1.2.1.2.1.1.5.1.6.1.1.1. The other ones were coded according to the developed code system, example of which is displayed in the table 2.

Table 2. Example of the code system

\begin{tabular}{|l|c|c|c|c|c|}
\hline Code & Collar & Code & Hood & Code & Form \\
\hline 1 & No collar & 1 & Stitched hood & 1 & Rectangular \\
\hline 2 & Convertible collar & 2 & Stitched hood with fur & 2 & Trapezoid (long base down) \\
\hline 3 & Standing straight collar & 3 & Removable hood & 3 & Oval \\
\hline$\ldots$ & $\ldots$ & 4 & Removable hood with fur & 4 & X shaped \\
\hline$\ldots$ & $\ldots$ & 5 & No hood & $\ldots$ & $\ldots$ \\
\hline
\end{tabular}

The procedure of categorical principal components analysis simultaneously quantifies categorical variables while reducing the dimensionality of the data. The importance of dimensions is sorted as it displayed in the figure 7 . The most important dimension 1 refers to the 


\section{IRTIIE}

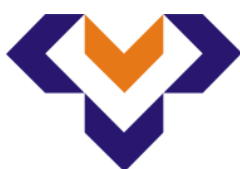

Ipplied Reserer rhes in Technics, Technologies and Bduration

Journal of the Faculty of Technics and Technologies, Trakia University https:///ites.google.com/a/trakia-uni.bg/artte/

component 1 that is "form" and the second one, dimension 2, refers to the component 2 that means "fastenings". The component loadings of the dimensions are shown in the figure 8.

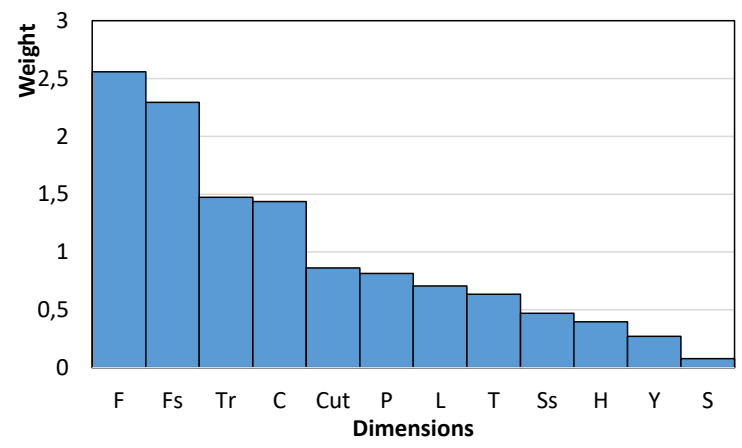

Figure 7. Importance of dimensions

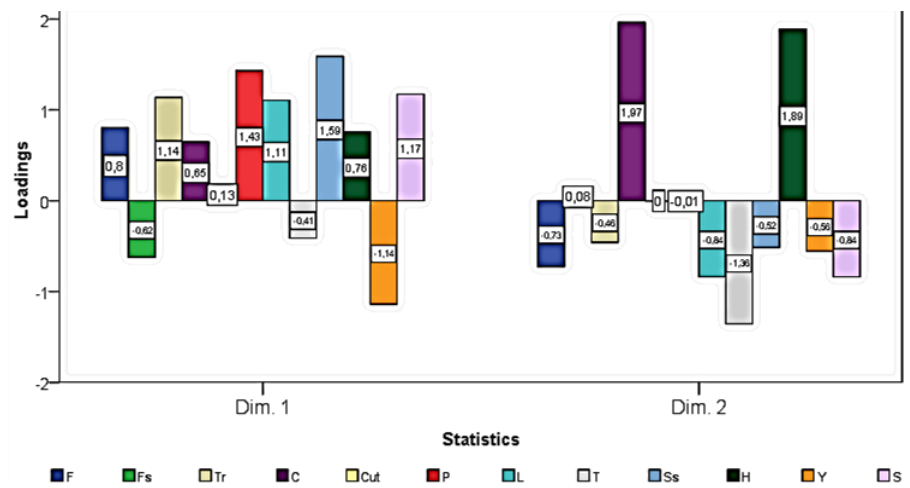

Figure 8. Loadings of the principal components

Thus, two most important components, which show the combined impact of all considered features, were selected out as dimensions for the graphical visualisation of the results of the current research.

Besides that, photos of clothes were valued using valuation factors in bipolar scales defined by verbal antonyms of Kansei words. Thus, each image was represented as a list of the average meanings of the estimated coefficients of semantical differential, which is called psychographic profile, for six pairs of Kansei words: symmetry - asymmetry (SA), bright - soft (BS), casual - smart clothes (CS), transparent - non-transparent (TN), folk - modern clothes (FM), trapezoid shape (long base down) - trapezoid shape (long base up) (TdTu). The garment that was the origin of search has a profile like follows: -3.0.-1.3.-2.-3. The procedure of categorical principal components analysis allowed selecting two dimensions, which are TdTu and BS, as well as estimating the loadings of the principal component (table 3).

Table 3. Loadings of the principal components (for the impressions from clothes)

\begin{tabular}{|l|c|c|c|c|c|c|}
\hline Component & TdTu & BS & FM & CS & TN & SA \\
\hline 1 & 0.970 & -1.240 & 1.191 & 1.354 & -0.437 & 0.280 \\
\hline 2 & -0.885 & 0.538 & 0.947 & 0.518 & 1.489 & 1.243 \\
\hline
\end{tabular}




\section{ARTTIE $Y$}

Ipplied Resseirlores in Technics, Technologies and Educration

Journal of the Faculty of Technics and Technologies, Trakia University https://sites.google.com/a/trakia-uni.bg/artte/

\section{RESULTS}

Objects plots (figure 9) display the differences between clusters of images. Objects are labelled with the category indicator values. One object plot is produced per variable, which is the feature of garment.
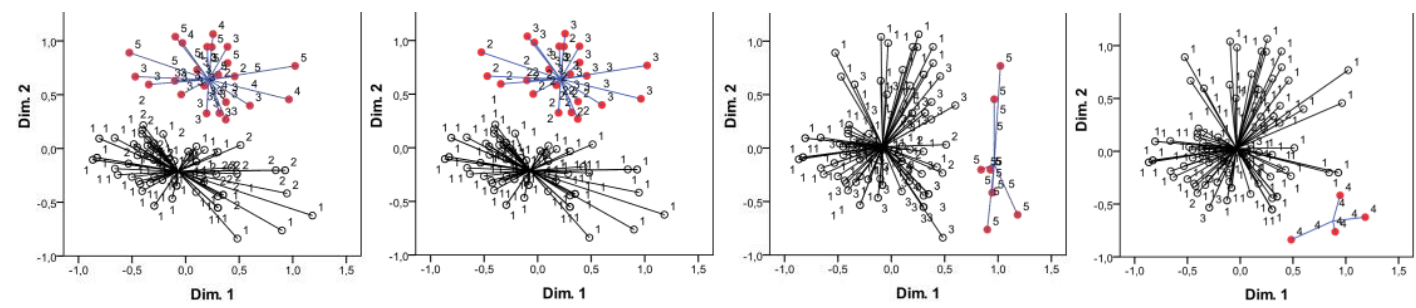

Figure 9. Results of the Categorical principal components analysis based on codes of garments: a) hood; b) collar; c) style seams; d) form

Each graph in the figure 9 displays two clusters that differ significantly by one of the follows features: F, SS, C, or $\mathrm{H}$. The form and the style seams are the features that cause the change of garment draft and the style. Particularities of the collar and hood cause differences in assembly techniques and a marker for the cutting. The size of each cluster that differs is considerable in comparison to the general size of the examined population of images. The number of items, which differ by features of the collar and hood, is 26 garments that is about $25 \%$ of the population of examined images of the duffle coats. The number of items, which differs by features of the form and style seams, is lesser. It is only four items for the form and eight items for the style seams, which compose a small cluster of ten images. It is about $10 \%$ of the population of the duffle coats. However, because of all these differences a considerable part (about $72 \%$ ) of the original population of the search results, which are displayed in the figure 6 , is of no use for the garment industry.

On the other hand, the graphs in the figure 11 display that all found images of the duffle coats cause the similar consumer's impressions from clothes. Several items, which differ from the main cluster by certain impression like TN "transparent - non-transparent" (figure 10, a) or "trapezoid shape (long base down) - trapezoid shape (long base up)" (figure 10, b), compose a small proportion that is insignificant in the general population of examined images. The part of each one is about $3 \%$ and $2 \%$ respectively.
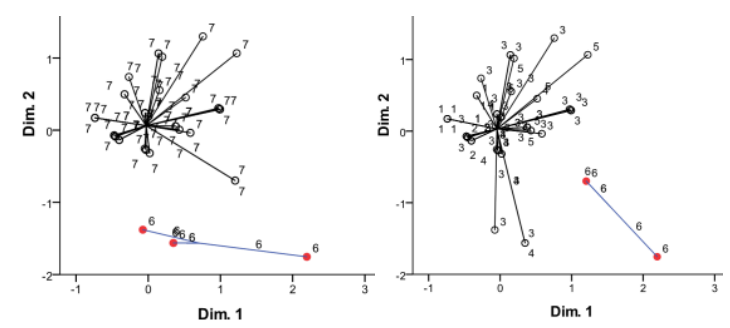

Figure 10. Results of the Categorical principal components analysis based on consumer's impressions of garments images: a) TN; b) TdTu

Therefore, it is impossible to disagree with the statement of [6] about the need to consider every single fashion item as a whole concept that has to do with human perception of contemporary world. 


\section{ARTTRY $Y$}

Ipplied Resseirlores in Technics, Technologies and Educration

Journal of the Faculty of Technics and Technologies, Trakia University https://sites.google.com/a/trakia-uni.bg/artte/

\section{CONCLUSIONS}

As a result of the current research, it was displayed that deep learning has many applications in contemporary world, which include the tasks of predicting the fashion as well as analysing the images of outfits and forming the textual description of the sketch. The task of organising the database of properly labelled images of garments is the first step to performing automatic fashion reviews, online searching and forming descriptions of garments. Based on the results of performed online survey, it was considered advisable to use as labels specific features of the particular garment type rather than its name because the features are standard and can be determined specifically.

Analysis of images of outerwear, which were obtained with the help of reverse image search, was conducted and images of women's duffle coats were selected. The selected material was sampled for the next categorical principal components analysis and general assessment of differences that are caused by specific features of garments. As a result of the analysis, it was determined that less than $30 \%$ of original population of images were sampled with required level of accuracy. However, all found images of the duffle coats cause the similar consumers' impressions. Hence, although it is certain that deep learning has great future in domain of apparel design, for now it can be used only for the purposes of similarity search for the online shops, which are oriented to the consumers' impressions rather than to retrieving the features of fashionable outfits.

\section{REFERENCES}

[1] Afanasieva N.V., \& Kuzmichev V.E. (2005). Development of the algorithm of recognition of the modern forms of the women's coats. Proceedings of Russian Scientific and Technical Conference on Modern Technologies and Equipment of the Textile Industry (TEXTILE-2005). Moscow State Textile University named after Kosygin, Moscow, November 20-23, (2005), pp. 343.

[2] Bengio Y., LeCun Y., \& Hinton G. (2015). Deep Learning. Nature, No. 521, (2015), pp. 436-444. doi:10.1038/nature14539.

[3] Firman T., \& Getmanskyi V. (2016). Designing Apparel with Neural Style Transfer. [Online]. Available: http://labs.eleks.com/2016/09/designing-apparel-neural-styletransfer.html [2017-08-03].

[4] Google Trends (2017). [Online]. Available: ttps://trends.google.com.ua/trends/ [2017-08-04].

[5] Grana C., Manfredi M., Calderara S., \& Cucchiara R. (2015), Garment Selection and Color Classification.

[Online].

Available: http://imagelab.ing.unimore.it/imagelab2015/researchactivity.asp?idAttivita=18 [2017-08-03].

[6] IBM SPSS Statistics - Essentials for Pyton 24.0 [Windows XP]. [Online]. Available: https://www.ibm.com/us-en/marketplace/statistical-analysis-and-reporting [2017-08-03].

[7] Kuleshova S. G., Zakharkevich O. V., Koshevko J. V. \& Ditkovska O. A. (2017). Development of expert system based on Kansei Engineering to support clothing design process. Vlakna a Textil, No 4, (2017), pp.30-41.

[8] Picalica Blog » Deep Learning Opportunities in Fashion (2014), [Online]. Available: https://www.picalike.com/blog/2014/02/20/deep-learning-opportunities-in-fashion/ [2017-0803].

[9] Romaniuk O. (2017). Fashion and Technology: How Deep Learning Can Create an Added Value in Retail. [Online]. Available: http://labs.eleks.com/2017/05/fashion-technologydeep-learning-can-create-added-value-retail.html [2017-08-03].

[10] Search for images with reverse image search - Google Search Help. [Online]. Available: https://support.google.com/websearch/answer/1325808?hl=en [2017-08-07]. 


\section{IRTIIE}

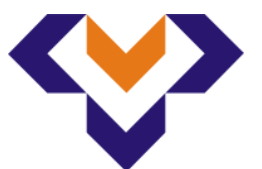

Ipplied Resererr'ches in Technics, Technologies and Bduration Journal of the Faculty of Technics and Technologies, Trakia University https:///ites.google.com/a/trakia-uni.bg/artte/

[11] Smirnov E., Kulinkin A., Ivanova K. \& Pogrebnyak M. (2016). Deep Learning for Fast and Accurate Fashion Item Detection. [Online]. Available: https://kddfashion2016.mybluemix.net/kddfashion_finalSubmissions/Deep\%20Learning \%20for\%20Fast\%20and\%20Accurate\%20Fashion\%20Item\%20Detection.pdf. [2017-0803].

[12] What is deep learning? I SAS. [Online]. Available: https://www.sas.com/en_za/insights/analytics/deep-learning.html [2017-08-08].

[13] Zakharkevich O. V. (2012). Developing of rational transformations chains of the women's shoulder clothing. Herald of Khmelnytskyi National University, No. 2, (2012), pp. 73-76. 